Article

\title{
Extending the 4I Organizational Learning Model: Information Sources, Foraging Processes and Tools
}

\author{
Tracy A. Jenkin \\ School of Business, Queen’s University, Kingston, ON K7L 3N6, Canada; \\ E-Mail: tjenkin@business.queensu.ca; Tel.: +1-613-533-6251; Fax: +1-613-533-2755
}

Received: 1 July 2013; in revised form: 5 August 2013 / Accepted: 15 August 2013 /

Published: 27 August 2013

\begin{abstract}
The continued importance of organizational learning has recently led to several calls for further developing the theory. This article addresses these calls by extending Crossan, Lane and White's (1999) 4I model to include a fifth process, information foraging, and a fourth level, the tool. The resulting 5I organizational learning model can be generalized to a number of learning contexts, especially those that involve understanding and making sense of data and information. Given the need for organizations to both innovate and increase productivity, and the volumes of data and information that are available to support both, the $5 \mathrm{I}$ model addresses an important organizational issue.
\end{abstract}

Keywords: organizational learning; knowledge management; information foraging; information sources; supporting tools

\section{Introduction}

There have recently been calls in the literature to build upon and extend existing theories of organizational learning. Vera et al. [1], for instance, calls for more integration between overlapping concepts of organizational learning, knowledge management, absorptive capacity, and dynamic capabilities and proposes a framework to do so. Crossan et al. [2], on the other hand, critically reflect upon how their 4I model of organizational learning [3] has been used and adapted over time, and identify gaps in the theory base. 
Crossan et al. [2] suggest ways for extending organizational learning (OL) theory to solidify the theoretical "trunk and base". "A theory of OL is more about a well-grounded trunk than it is about adding to the complexity of branches and leaves. Indeed, adding more branches and leaves creates the need for an even stronger and sustainable trunk and base to support them” ([2], p. 454). Some past research does focus on strengthening the theoretical trunk by deepening our understanding of the 4I learning processes (e.g., understanding how power works within each of the four processes [4]) or broadening the model to include additional key processes and levels (e.g., adding the inter-organizational level [5]). Much of the past research, however, develops the branches and leaves of the theory [2] by examining organizational learning in different contexts or treating organizational learning as a factor that influences another focal research phenomenon (e.g., entrepreneurial opportunity recognition [6]). In this, organizational learning is at best only examined peripherally. To further strengthen and broaden the trunk, Crossan et al. [2] highlight the importance of developing multi-level theories and adopting an evolutionary approach for organizational learning. This paper seeks to broaden the theoretical trunk by proposing a 5I model that extends the existing 4I organizational learning model in a manner consistent with these recommendations [2].

The 4I organizational learning model has been highly cited, shaping thought and research in the area of organizational learning. However, according to Crossan et al. [2] relatively few of these articles attempt to build upon the 4I model: Those that do have explored different research avenues, for example elaborating on the learning processes themselves, and examining the factors that enable or inhibit organizational learning. One area that has received minimal attention is the triggering mechanisms for the intuiting process. In other words, what spurs the individual to engage in intuiting, creating the potential for organizational learning? Of the four learning processes, it is arguable that intuiting is the most difficult to study due to its subconscious and pre-verbal nature [3]. As a result, studying the triggers to intuiting is also challenging, which may account for the limited research in this area. Zeitsma et al. [7] move in this direction by adding an attending process to the 4I model. Specifically, they look at how individuals attend to external stimuli or alternative and conflicting viewpoints (e.g., the opinions of protestors), which in turn affects intuiting and organizational learning.

The fact that organizations are faced with a proliferation of data and are beginning to focus on investing in "big data" and "data analytics" [8] point to the need to better understand how these sources of data and information can promote learning and trigger intuiting. We extend beyond attending processes [7] and examine a more active engagement with the environment, information foraging. Thus, we propose a fifth process, information foraging, which captures how individuals engage with sources of data and information as part of the learning process. Tools are often used to access or process this data and information so that it can be appropriately utilized. In addition, tools may be useful in supporting other learning processes at the individual, group and organizational levels [9]. Thus, we propose a fourth level to the 4I organizational learning model: the tool level.

Building upon Crossan et al.'s [3] 4I model, this conceptual paper proposes a 5I organizational learning model, adding both an information foraging process and a tool level. These extensions help explain the precursors to intuiting as well as the roles that tools can play in supporting learning at the individual, group and organizational levels. The proposed 5I model addresses the calls for extending and building theories of organizational learning, as well as integrating organizational learning and knowledge management concepts. The resulting 5I model retains the multilevel homologous nature of 
the 4I organizational learning model while incorporating additional evolutionary processes. This 5I model can be generalized to a number of different learning contexts that involve understanding and making sense of data and information, which is a critical issue given the large volumes of data and information available to organizations.

This paper is organized as follows. We begin by describing the 4I organizational learning model and our proposed extensions to it. Next, we discuss how the proposed 5I model addresses the requirements stipulated in past research for building a stronger organizational learning theory base. Lastly, we discuss the implications and potential future research avenues suggested by the proposed 5I organizational learning model.

\section{Extending the 4I Organizational Learning Model}

In the section below, we explore in more depth the precursors to the intuiting process and propose extensions to the $4 \mathrm{I}$ organizational learning process, resulting in the $5 \mathrm{I}$ model. We begin by describing the existing 4I model.

\subsection{Learning Processes}

The 4I model conceptualizes organizational learning as a multi-level dynamic process, including both feed-forward and feedback processes [3]. These processes span the individual, group and organizational levels, and include intuiting, interpreting, integrating and institutionalizing processes. At the individual level, intuiting marks the beginning of the feed-forward process. Intuiting involves pattern recognition and the development of insights, resulting in initial inklings of interesting possibilities. The process of interpreting involves developing models for understanding, bringing out meaning, and developing shared mental models amongst managers [3,10]. Interpreting follows intuiting and begins as an individual process and can move to a group process where ideas are formed, articulated, discussed and debated. Thus, interpreting leads to updated mental models (i.e., frameworks or knowledge structures to help organize information [3,11-13]) at the individual and group level. The next process, integrating, is a group process where a shared understanding is translated into coordinated action, for example, executing a new product or process-related idea. The last process, institutionalizing, occurs at the organizational level when learning becomes embedded into routines, rules, procedures, infrastructures as well as the organizational "code” [14].

What is not included in the 4I model are the triggers to intuiting. We conceptualize these triggers along two dimensions: (1) intentionality and (2) mechanism. Intentionality refers to the degree to which the individual is consciously and actively seeking triggers. For example, individuals may actively seek information for some purpose (e.g., performing a database query to identify outliers in sales data), or they may be simply going about their daily routine and encounter information serendipitiously, which then triggers intuiting (e.g., receiving an email from a colleague that stimulates intuiting). Mechanism, on the other hand, refers to whether the trigger is experiential (i.e., based on experience, for example, managing a project) or informational in nature (i.e., based on access to information sources, for example, reviewing the results of a database query).

Beyond the $4 \mathrm{I}$ model, other learning models have included processes such as scanning, learning [10], reconceptualizing the problem, deciding to search, search and evaluate [15], attending, 
experimenting [7], searching and noticing [16]. Some of these other learning processes may precede and trigger intuiting. The scanning, searching, noticing and evaluation processes can be conceptualized more broadly as information foraging. Information foraging, based on the "optimal foraging theory" from biology and anthropology, refers to the process of seeking information, as well as assessing and choosing information sources based on the expected value of information and expected cost of locating and extracting this information $[17,18]$. Information foraging is an evolutionary process that involves identifying an initial source and search-space, browsing the search-space to identify the required information and, if required, reformulating the search terms to refine and narrow the search space [19]. The search strategy adapts to the constraints and affordances of the task including complexity and the expected value of information and cost of searching. As a trigger to intuiting, information foraging represents a conscious effort to seek information and typically relies on an information-based mechanism.

Information foraging describes the process by which information sources and search spaces are chosen, navigated and assessed. Attending is a related process that also relates to intuiting. As noted above, attending refers to paying attention and noticing external stimuli. How the individual attends to external stimuli influences the intuiting process [7]. When individuals are consciously seeking information-based triggers, attending occurs as part of the information foraging process. As the individual navigates the information source, they attend to the information found, assessing whether it warrants further examination and thought. They also attend to and follow the information scent, that is, cues and metaknowledge along the existing path that help the individual decide how to proceed $[18,20]$. However, when individuals are not consciously seeking triggers, attending is a distinct process where individuals notice and choose whether to pay attention to discrepancies or issues that arise in the environment (see [7]).

Since organizations are currently exposed to vast quantities of data, information-based triggers, such as information foraging, appear to be particularly important and relevant. Past research has looked at information foraging and individual learning outcomes, as well as how the individual makes sense of the information scent during the information foraging process [21,22]. We extend this past research by integrating information foraging into the $4 \mathrm{I}$ organizational learning model as a fifth process, as well as examining how it contributes to the feed-forward process of learning and is affected by feedback processes. The information foraging process requires an information source and a tool to support the "foraging" of the search-space. We discuss these sources and tools next.

\subsection{Information Sources and Tools}

The large volumes of data (i.e., raw transactions and observations) and information (i.e., data that has been structured and given meaning) available both inside and outside the organization make it an important source of learning for both individuals and, in turn, organizations. Broadly speaking, sources of information can be classified as internal or external to the organization, and as personal or impersonal $[10,23]$. The benefits and challenges vary with each type of source [23].

Personal sources of information refer to engaging with people to acquire information and knowledge, either explicit (i.e., codified knowledge, articulable in spoken or written form) or tacit (i.e., highly personal and embodied knowledge, including mental models, know-how, craft and skills) [24-26] in nature. The concept of knowledge sourcing, defined as "the extent to which an individual accesses 
other employees' expertise, experience, insights, and opinions” ([27], p. 821), focuses directly on personal sources. "Knowledge sourcing is an indirect learning behavior where individuals gain access to others' understanding of the work environment, mostly through language-based interactions” ([27], p. 822). This type of source involves accessing the expertise of individuals or groups within the organization or external to it.

Impersonal sources, on the other hand, involve accessing data and information through explicit and codified sources such as documents, webpages, databases, and other sources of data or information. These sources can also be internal or external to the organization. The exponential growth in data collected by organizations has led to both academic and practitioner interest in the areas referred to as "big data” and "data analytics" [8]. The Web is another source of valuable external and impersonal information that can be leveraged by organizations for learning about the environment and innovation [28].

Based on these dimensions, there are four major types of information sources: personal-internal, personal-external, impersonal-internal and impersonal-external. For each type of source, there exist tools to help individuals access and process the information into a usable form (see Table 1 for examples). Tools oriented to personal sources of information focus on locating, communicating and coordinating with individuals. Tools for impersonal sources focus on locating the data or information and, in some cases, processing the data into a usable format. For example, data analysis tools locate the required records and fields and summarize them for the user. Pattern-based task management systems allow users to search for workflow patterns and templates used for different tasks in the organization [9].

Table 1. Examples of Tools Used for Accessing and Processing Information.

\begin{tabular}{|c|c|c|}
\hline & Internal & External \\
\hline Personal & $\begin{array}{c}\text { Collaborative technologies, internal } \\
\text { directories and experts database }\end{array}$ & $\begin{array}{c}\text { Collaborative technologies, } \\
\text { social media sites, external directories }\end{array}$ \\
\hline Impersonal & $\begin{array}{l}\text { Enterprise content management tools, } \\
\text { document summarization tools, data } \\
\text { mining tools, data analysis tools, } \\
\text { pattern-based task management }\end{array}$ & $\begin{array}{l}\text { Basic search engines, knowledge maps and } \\
\text { clustering tools, document summarization } \\
\text { tools, competitive intelligence systems, tagging }\end{array}$ \\
\hline
\end{tabular}

Given the relationship between information foraging processes and information sources, as well as the reliance on tools to access and navigate those sources, the proposed 5I organizational learning model includes a fourth level: the tool level. We describe the proposed 5I model below.

\subsection{The 5I Organizational Learning Model}

Information foraging extends the feed-forward process and is intricately linked with the individual learning process of intuiting. To initiate information foraging, a goal must be articulated even if it is exploratory and vague in nature [29]. Driven by this goal, search terms, or other criteria to guide the foraging process, are developed by the individual through an intuitive and inductive process. Information foraging is an evolutionary and iterative process that spans the individual and tool levels. Given the large volume of information and information sources noted above, tool support for the information foraging process is critical. For example, data analysis tools help retrieve and summarize 
database records, and search engines quickly locate websites that are highly relevant to the search terms entered. Individuals tend to rely on tools to locate information; the individual then assesses the information that is returned.

The information foraging process highlights the roles that individuals and tools each play as actors in the co-production of results; neither the tool nor the individual are solely responsible for the production of the results, but co-produce them. For example, when retrieving data from a database using some type of structured query language and tool, individuals provide direction to the tool. The tool acts on these directions to retrieve the results, navigating through the information source using a complex set of rules and logic. The individual then assesses the results that are returned by that tool. On the Web, individuals provide search terms to a search engine and that search engine uses these terms to navigate the complex structure of the Web to retrieve the results. The individual assesses the list of webpages that are returned, making decisions about which documents to explore in more depth or paths to follow. Metaknowledge (i.e., contextual clues about the results) such as tags (i.e., key words attached to content by individual users) will help users with these navigational decisions [21,22]. Thus, information foraging involves interaction between tools and individuals, who are jointly responsible for co-producing the results. The information foraging process is iterative. If additional or different results are sought, another iteration of information foraging is enacted by the individual, who provides updated criteria to the tool. For example, when the results of a Web search do not meet the user's expectations, he or she alters the search terms and criteria, provides them to the tool, and repeats the process. Successful search strategies, that is, configurations of tools, search criteria, and information sources, are preferentially selected thereby influencing future behaviors. Individuals, and in some cases tools, adapt their search strategies based on what has worked well in the past and on the current search context. For example, Google uses information about individuals’ previous search behaviors.

Beyond this, a deeper assessment of the results spans both the individual intuiting and interpreting processes. During intuiting, patterns, relevance and the potential importance of the information are assessed, whereas in interpreting, these initial thoughts are crystallized into ideas and updated mental models. Additional searches, or iterations of information foraging, may be needed to further develop these ideas. Thus, the information-foraging, intuiting and interpreting processes are connected with a loop to reflect the iterative nature of the relationship (see Figure 1).

In addition to its role as an actor in co-producing results, tools may also have the ability to support or facilitate intuiting and interpreting processes. For example, advanced search engines such as those that cluster the results or present them in the form of a knowledge map (i.e., a graphical map with nodes as Web sites and lines between nodes representing common key words [28]), may facilitate to some degree the interpreting process - assigning meaning to information. A knowledge map can highlight clusters related to a topic and the relationships between these clusters, making it easier for the individual to understand and make sense of the topic, sub-topics and relationships between them. Tags and tag clouds can also help individuals make sense of the results [21,22,30]. It is also conceivable that some tools facilitate intuiting by highlighting patterns and drawing them to the attention of the individual user, as is the case with some data mining tools. Past literature highlights the multiple roles that tools can play (e.g., driver, facilitator, agent: [31]). 
Figure 1. Proposed 5I Organizational Learning Model.

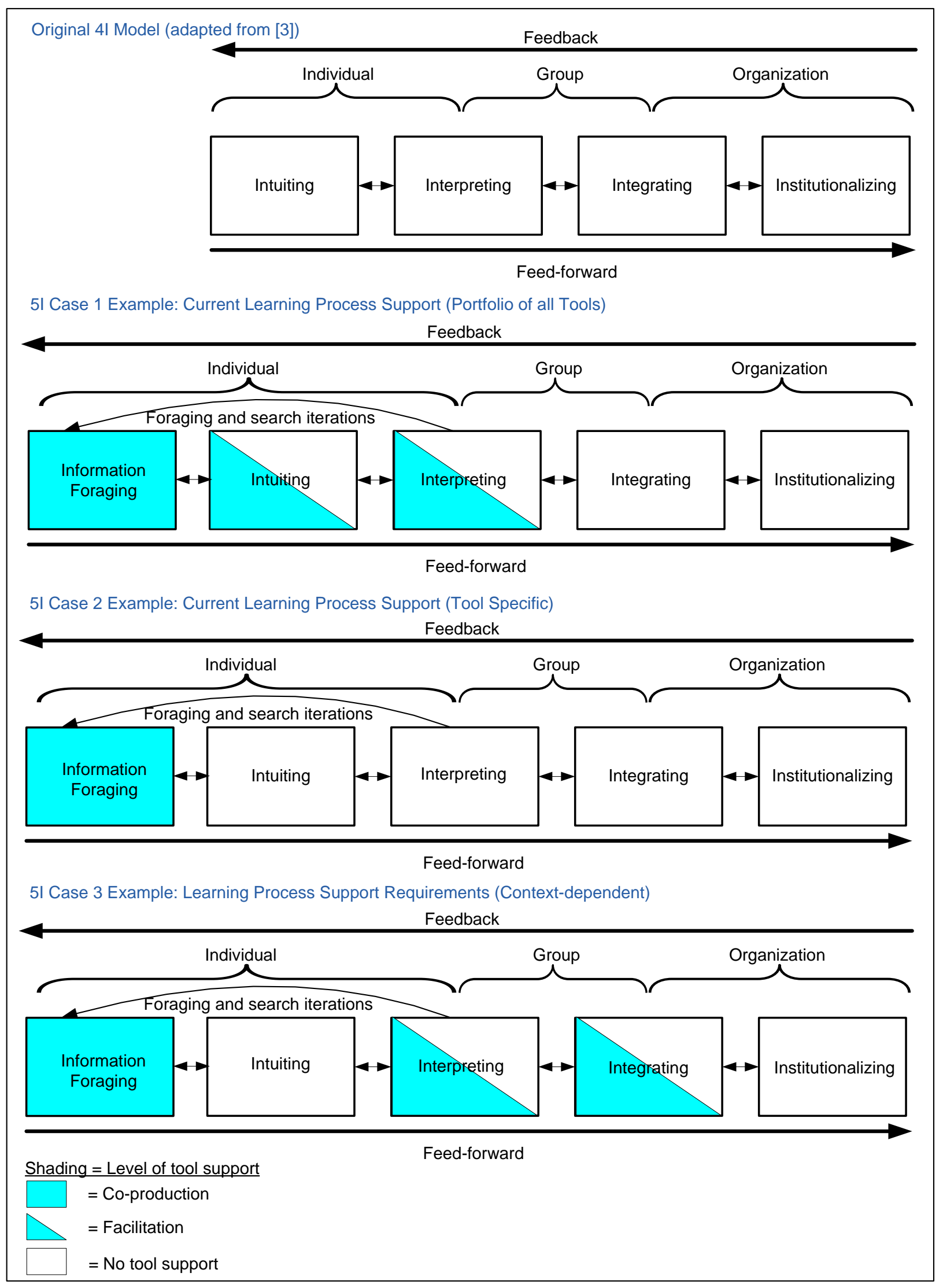

Beyond individual level processes, tools can also support learning processes at the group and organizational levels. At the group level, tools can help groups develop a shared understanding of 
ideas, for example, using group support systems and recently developed tools for mapping and displaying the opinions of group members [32]. Integration processes may be facilitated by collaboration or project management tools. Lastly, at the organizational level, institutionalizing processes, where new ideas are embedded into routines, rules and procedures, etc. may be facilitated by pattern-based task management tools [9] and information systems that embed new organizational processes into enterprise applications. Thus, it is useful to consider how tools can support learning at all levels.

Figure 1 depicts these proposed extensions to the $4 \mathrm{I}$ learning process model [3]. Information foraging, as discussed above, precedes intuiting but is connected to intuiting and interpreting by a loop to reflect the iterative nature of this process. The tool level is modeled by the degree of shading in each of the five learning processes, reflecting the type of support provided. Similar to Gago and Rubalcaba [31], we define three levels of support: none, facilitation, and co-production. For example as discussed above, search engines tend to play a co-producer role for information foraging processes (full shading). Group support systems, on the other hand, tend to play a facilitating role for group interpretation processes (partial shading). Although tools that play facilitation roles are less active and dominant in the learning process than those in co-production roles, both are important.

There are different ways this model can be used. From a diagnostic perspective, the model could be used to either depict where and how an organization currently uses tools to support these five learning processes (case 1, Figure 1), or how a particular tool provides support to each of these processes (e.g., how does a search engine provide support) (case 2, Figure 1). Alternatively, the model could be used to depict ideal learning contexts. Since an organization's learning needs vary by context (e.g., size, structure, strategy, etc.), the types of tool support required to meet these needs will also vary. Thus, the model could be used to depict these context-dependent tool support requirements (case 3, Figure 1). Mapping current tool learning support against the support requirements can help organizations identify gaps that require attention.

\section{Discussion and Conclusions}

Including a fourth level (tool) and fifth learning process (information foraging) address the

recommendations put forth by Crossan et al. [2] for strengthening and extending organizational learning theory: (1) multi-level modeling; and (2) evolutionary approaches. Regarding multi-level modeling, our extensions add another level, the tool level. Our extensions also support the existing homologous multi-level (i.e., "relationship between two variables holds at multiple levels of analysis” ([33], p. 219) nature of the model. The existing 4I model has many elements that, we argue, fit with the homologous type (as opposed to single level, cross-level direct, cross-level moderator, and cross-level frog pond models) of multi-level models [33]. For instance, the feed-forward process links the individual, group and organizational levels of analyses. Specifically, through this feed-forward process mental models are progressively articulated, changed and shared between levels. In turn, the feedback process reflects how existing mental models shape and constrain learning at each level. The feed-forward and feedback processes model the ongoing tension between exploration and exploitation [14]. The feed-forward process of organizational learning is an exploratory process that translates individual and group insights into learning that is institutionalized via "organizational learning systems" [3,14]. The 
feedback process exploits institutionalized learning, which guides individual and group thinking and action [3]. However, institutionalized routines, norms and mental models are slow to change and, thus, may constrain future learning and exploration [3,14,34].

Our proposed $5 \mathrm{I}$ model builds on these feed-forward and feedback processes. The results provided to the individual during information foraging, an information model of sorts and representation of existing knowledge, can influence and change the individual's mental model in the feed-forward process. In the feedback process, existing mental models at the organizational, group and individual levels will influence the goals and the search terms that form the input to the information foraging process. Current mental models also affect how the results are assessed [21,22]. Thus, in the feedback process, what has been learned in the past and embedded into existing mental models guides both what we search for and how we interpret the results. Beyond this, at some level, what has been learned in the past becomes incorporated into the information sources (i.e., content) used during information foraging. For example, tag clouds represent the collective and accumulated knowledge of individuals who tagged a particular source in the past [9].

The second requirement for organizational learning theories stipulated by Crossan et al. [2] is that they reflect the evolutionary nature of learning, including processes of variation, selection and retention. Our proposed 5I model addresses this requirement. Information foraging, as discussed above, is in itself an evolutionary process. Beyond this, the information sources and tools leveraged in the information foraging process provide a source of variation; individuals and their organizations can choose between a large number of different information sources and tools. Those sources and tools that prove most valuable will be selected and embedded into routines. For example, an organization will choose to use a standard data analysis tool and individuals will tend to use tools and sources that have worked well in the past. Similarly, the information acquired through the information foraging process enables the individual to generate a variety of ideas. The existing 4I model explains how those ideas will be selected for their value to the organization through the interpreting, integrating and institutionalizing processes. At the most granular level, there is variety in the data itself; the ongoing data generation processes result in a constant flow of data into the organization, which allows the organization to adapt to the environment.

As noted by Vera et al. [1], there is value in integrating concepts across the organizational learning, knowledge management, absorptive capacity and dynamic capabilities domains. In this case, we integrate concepts between organizational learning and knowledge management by modeling how the vast sources of data and information and associated tools trigger the learning process. Similarities between the 4I model and Nonaka's [25] organizational knowledge creation process (SECI) have been identified in the past (e.g., [35]). Examining how Nonaka's four knowledge creation processes relate to our proposed 5I model can help deepen the connections between the organizational learning and knowledge management domains and enrich our understanding of these processes. Figure 2 overlays Nonaka's four processes on the proposed 5I model. The combination, internalization and externalization knowledge creation processes explain the interface between information foraging and intuiting. At the beginning of the process the individual makes their tacit knowledge explicit (externalization) by articulating a goal, search terms and criteria. During the information foraging process, assuming the focus is on impersonal sources, information (i.e., explicit, codified knowledge) is brought together from different sources (combination). This information is absorbed by the 
individual, who internalizes it as tacit knowledge, updating their mental models (internalization). As ideas are generated at the individual and group levels, this tacit knowledge is once again transformed into explicit knowledge as articulated ideas (externalization). As these ideas are put into action, they are once again transformed into tacit knowledge as individuals learn by doing (internalization). Lastly, during institutionalizing, individuals transfer their tacit knowledge through their shared experiences with organizational routines, policies, etc. that are the result of the learning process (socialization).

Figure 2. The 5I and SECI Models.

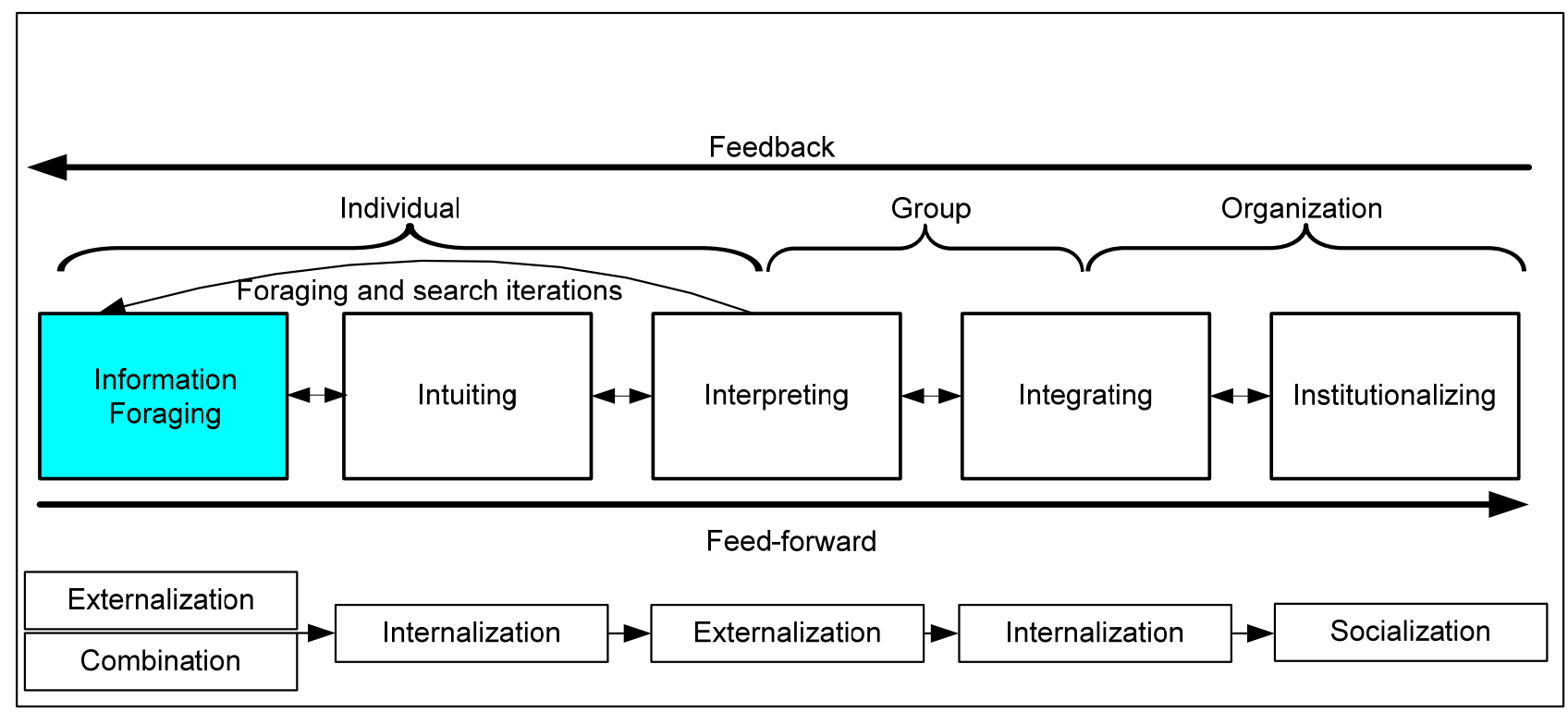

The predominance of the internalization-externalization cycle across the five organizational learning processes aligns well with Nonaka's [25] organizational knowledge creation process. He notes that "knowledge creation centers on the building of both tacit and explicit knowledge and, more importantly, on the interchange between these two aspects of knowledge through internalization and externalization” ([25], p. 20). Although all four creation processes are involved, internalization and externalization are key in the amplification of knowledge from the individual to the group and organizational levels. That being said, combination and socialization may also play supporting roles in some of these processes and may be influenced by the type of learning tools used. For example, tools that focus on personal sources of information may result in more socialization processes, whereas a focus on impersonal sources may result in combination. Thus, whether additional combination and socialization processes are involved depends on the learning and organizational context.

\subsection{Implications and Future Research}

As discussed above, our proposed 5I model contributes to the organizational learning domain by addressing calls for extending theory. The proposed 5I model can be generalized to a number of different learning contexts, including those related to learning from big data, open innovation, and social media, for example. Within these contexts, understanding how learning is triggered from sources of data and information is an important organizational issue given the large volumes of data and information available. Future research should explore these learning contexts and the usefulness of 
the proposed 5I model. Examining the model in a variety of contexts that require different sources, for example personal-external versus impersonal-internal sources, may help identify additional ways to extend the model. In addition, examining whether the proposed 5I model, the SECI model, or a combination of the two is best at exploring these learning contexts and related issues would be valuable.

Using the proposed 5I model to examine cases of organizational learning in the field may highlight a variety of learning challenges. One potential challenge that organizations may face is that once employees familiarize themselves with a set of tools and/or information sources, it may be difficult for them to explore beyond those sources and tools. This challenge was noted by a participant in recent case research: "I think that a lot of people are too myopic in 'I know this, I use this, if it's not here then we don't have it'.” Future research should explore these learning issues and how they can be addressed.

At a tool level, the proposed 5I model provides flexibility in modeling the level of tool support for the five learning processes. Understanding which types of tools might be useful for different learning contexts, information sources, and processes may assist practitioners in developing their knowledge management strategy and systems, and enable them to "manage" their learning [36]. For example, understanding the features that help facilitate intuiting, for instance, could help with tool design. In addition, using the 5I model to assess gaps between current learning process support and learning support requirements would help organizations discover areas that require attention. Future research should examine tools that support learning, either in co-producing or facilitating roles, for each of the five learning processes, as well as the usefulness of the framework as a diagnostic tool for practitioners.

\subsection{Concluding Remarks}

Building on the highly-cited 4I model [3], this conceptual paper proposes a 5I organizational learning model by adding an information foraging process and a tool level. These extensions help explain the precursors to intuiting and can be generalized to many learning contexts that involve seeking data, information and knowledge from a variety of sources. The model also highlights the different roles that tools can play in supporting learning processes at the individual, group and organizational levels.

Organizations are faced with a host of emerging issues that require the development of new knowledge and ideas, as well as leveraging existing knowledge and resources. These emerging issues include waning innovation [37], increasing institutional pressures related to environmental sustainability [38,39], and rising consumer demand from high-growth markets [40] amongst others. By better understanding how organizations learn from information sources, including how tools can be leveraged in either co-production or facilitation roles, we can potentially help organizations address these emerging issues. For example, the capability to learn from large volumes of data and information may help organizations improve their innovation processes both in terms of efficiency and effectiveness and address concerns over waning innovation [37]. Learning from data and information could also help organizations gain operational efficiencies and, in turn, increase productivity so that they can meet the increasing consumer demand from high-growth markets [40]. Lastly, improvements in innovation and operational efficiency can both contribute positively to environmental sustainability. 


\section{Acknowledgments}

The author would like to thank Yolande Chan and Keith Rogers for helpful comments provided on earlier versions of this manuscript and is grateful to the Social Sciences and Humanities Research Council of Canada and The Monieson Centre, Queen's School of Business for funding provided.

\section{Conflicts of Interest}

The author declares no conflict of interest.

\section{References}

1. Vera, D.; Crossan, M.; Apaydin, M. A Framework for Integrating Organizational Learning, Knowledge, Capabilities, and Absorptive Capacity. In Handbook of Organizational Learning and Knowledge Management, 2nd ed.; Easterby-Smith, M., Lyles, M., Eds.; Wiley: Chichester, UK, 2011; pp. 153-180.

2. Crossan, M.M.; Maurer, C.C.; White, R.E. Reflections on the 2009 AMR decade award: Do we have a theory of organizational learning? Acad. Manag. Rev. 2011, 36, 446-460.

3. Crossan, M.M.; Lane, H.W.; White, R.E. An organizational learning framework: From intuition to institution. Acad. Manag. Rev. 1999, 24, 522-537.

4. Lawrence, T.B.; Mauws, M.K.; Dyck, B.; Kleysen, R.F. The politics of organizational learning: Integrating power into the 4I framework. Acad. Manag. Rev. 2005, 30, 180-191.

5. Jones, O.; Macpherson, A. Power and Inter-Organizational Learning: Intertwining New Knowledge. In MMU Research Institute for Business and Management Working Paper Series; Manchester Metropolitan University: Manchester, UK, 2005.

6. Lumpkin, G.T.; Lichtenstein, B.B. The role of organizational learning in the opportunity-recognition process. Entrep. Theory Pract. 2005, 29, 451-472.

7. Zietsma, C.; Winn, M.; Branzei, O.; Vertinsky, I. The war of the woods: Facilitators and impediments of organizational learning processes. Br. J. Manag. 2002, 13, S61-S74.

8. Laney, D.; Buytendijk, F. Invest in Information and Analytics to Benefit from Big Data. In Special Report: Big Data, Bigger Opportunities: Investing in Information and Analytics; ID: G00250120; Gartner: Stanford, CT, USA, 8 March 2013.

9. Kimmerle, J.; Cress, U.; Held, C. The interplay between individual and collective knowledge: Technologies for organisational learning and knowledge building. Knowl. Manag. Res. Pract. 2010, 8, 33-44.

10. Daft, R.L.; Weick, K.E. Toward a model of organizations as interpretation systems. Acad. Manag. Rev. 1984, 9, 284-295.

11. Day, G.S. Managing the market learning process. J. Bus. Ind. Mark. 2002, 17, 240-252.

12. Kim, D.H. The link between individual and organizational learning. Sloan Manag. Rev. 1993, 35, 37-50.

13. Hedberg, B. How Organizations Learn and Unlearn? In Handbook of Organizational Design; Nystrom, P.C., Starbuck, W.H., Eds.; Oxford University Press: London, UK, 1981.

14. March, J.G. Exploration and exploitation in organizational learning. Organ. Sci. 1991, 2, 71-87. 
15. Majchrzak, A.; Cooper, L.P.; Neece, O.E. Knowledge reuse for innovation. Manag. Sci. 2004, 50, 174-188.

16. Huber, G.P. Organizational learning: The contributing processes and the literatures. Organ. Sci. 1991, 2, 88-115.

17. Pirolli, P.; Card, S. Information Foraging in Information Access Environments. In Proceedings of The SIGCHI Conference on Human Factors in Computing Systems, Denver, CO, USA, 7-11 May 1995; ACM Press/Addison-Wesley Publishing Co.: New York, NY, USA, 1995.

18. Pirolli, P.; Card, S. Information foraging. Psychol. Rev. 1999, 106, 643-675.

19. Hoare, C.; Sorensen, H. Information foraging with a proximity-based browsing tool. Artif. Intell. Rev. 2005, 24, 233-252.

20. Pirolli, P. Computational Models of Information Scent-Following in a Very Large Browsable Text Collection. In Proceedings of the SIGCHI Conference on Human Factors in Computing Systems, Atlanta, GA, USA, 22-27 March 1997; ACM Press/Addison-Wesley Publishing Co.: New York, NY, USA, 1997.

21. Cress, U.; Held, C.; Kimmerle, J. The collective knowledge of social tags: Direct and indirect influences on navigation, learning, and information processing. Comput. Educ. 2013, 60, 59-73.

22. Held, C.; Kimmerle, J.; Cress, U. Learning by foraging: The impact of individual knowledge and social tags on web navigation processes. Comput. Hum. Behav. 2012, 28, 34-40.

23. Kourteli, L. Scanning the business external environment for information: Evidence from Greece. Inf. Res. 2005, 11, 1-16.

24. Collins, H.M. The structure of knowledge. Soc. Res. 1993, 60, 95-116.

25. Nonaka, I. A dynamic theory of organizational knowledge creation. Organ. Sci. 1994, 5, 14-37.

26. Polanyi, M. The Tacit Dimension; Doubleday: Garden City, NY, USA, 1966.

27. Gray, P.H.; Meister, D.B. Knowledge sourcing effectiveness. Manag. Sci. 2004, 50, 821-834.

28. Chung, W.; Chen, H.; Nunamaker, J.F., Jr. A visual framework for knowledge discovery on the Web: An empirical study of business intelligence exploration. J. Manag. Inf. Syst. 2005, 21, 57-84.

29. Kuhlthau, C.C. Inside the search process: Information seeking from the user's perspective. J. Am. Soc. Inf. Sci. 1991, 42, 361-371.

30. Jenkin, T.A.; Chan, Y.E.; Skillicorn, D.B.; Rogers, K.W. Individual exploration, sensemaking and innovation: A design for the discovery of novel information. Decis. Sci. 2013, 44, forthcoming.

31. Gago, D.; Rubalcaba, L. Innovation and ICT in service firms: Towards a multidimensional approach for impact assessment. J. Evol. Econ. 2007, 17, 25-44.

32. Jenkin, T.A.; Skillicorn, D.B.; Chan, Y.E. Novel Idea Generation, Collaborative Filtering, and Group Innovation Processes. In Proceedings of the Thirty Second International Conference on Information Systems, Shanghai, China, 4-7 December 2011; Association for Information Systems: Atlanta, GA, USA, 2011.

33. Klein, K.J.; Kozlowski, S.W.J. From micro to meso: Critical steps in conceptualizing and conducting multilevel research. Organ. Res. Methods 2000, 3, 211-236.

34. Crossan, M.M.; Berdrow, I. Organizational learning and strategic renewal. Strateg. Manag. J. 2003, 24, 1087-1105. 
35. Nemanich, L.A.; Keller, R.T.; Vera, D.; Chin, W.W. Absorptive capacity in R\&D project teams: A conceptualization and empirical test. IEEE Trans. Eng. Manag. 2010, 57, 674-688.

36. Zack, M.H. The strategic advantage of knowledge and learning. Int. J. Intell. Cap. Learn. 2005, 2, $1-20$.

37. Anonymous. Innovation Pessimism: Has the ideas machine broken down? The Economist, 12 January 2013.

38. Berry, M.A.; Rondinelli, D.A. Proactive corporate environmental management: A new industrial revolution. Acad. Manag. Exec. 1998, 12, 38-50.

39. Berrone, P.; Gelabert, L.; Fosfuri, A.; Gomez-Mejia, L.R. Can Institutional Forces Create Competitive Advantage? An Empirical Investigation of Environmental Innovation. In The Academy of Management Proceedings, Anaheim, CA, USA, 8-13 August 2008; Academy of Management: Briarcliff Manor, NY, USA, 2008.

40. Anonymous. Markets and makers: Running harder. The Economist, 20 April 2013.

(C) 2013 by the authors; licensee MDPI, Basel, Switzerland. This article is an open-access article distributed under the terms and conditions of the Creative Commons Attribution license (http://creativecommons.org/licenses/by/3.0/). 